\title{
A survey of admissions following self-poisoning
}

\author{
AIMS AND METHOD \\ Patients who self-poison are at \\ increased risk of future self- \\ poisoning and early death. Admission \\ patterns and effective treatment \\ strategies are unclear although \\ psychosocial assessment may reduce \\ readmissions. This study aimed to \\ determine admission patterns and \\ the proportion of patients receiving \\ a psychiatric assessment in 4220 \\ consecutive admissions.
}

\author{
RESULTS \\ The average age was 34 years \\ (s.d. $=13$, range $13-94)$; most were \\ female ( 56 v. $44 \%, P<0.001$ ). Twelve \\ per cent of patients were aged $13-18$ \\ years, again the majority were female \\ ( 70 v. $30 \%, P<0.001$ ). Twenty per cent \\ of patients had multiple admissions, \\ accounting for $42 \%$ of the total \\ admissions. There were slightly more \\ admissions per day at the weekend \\ (Friday, Saturday and Sunday;
}

\author{
$P<0.002$ ). As many as 245 patients \\ were either not referred or 'self- \\ discharged' before they were \\ assessed by the liaison psychiatry \\ service.

\section{CLINICAL IMPLICATIONS} \\ These findings may help target \\ medical resources, suggesting that \\ consistent numbers of staff are \\ required during all days of the week.
}

Self-poisoning is common (Hawton et al, 1997) and the most frequent cause of hospitalisation involving selfharm in the UK. Although most patients do not present with a life-threatening condition, and the need for urgent medical intervention is the exception rather than the rule, the majority require admission for observation. There are a significant number of readmissions with this condition; $15-23 \%$ of patients have a further admission within 1 year (Bialas et al, 1996; McEvedy, 1997; Van der Sande et al, 1997; Hawton et al, 1999). These patients represent a significant continuing danger to themselves, with around $4 \%$ dying by suicide in the subsequent $5-10$ years (Gunnell \& Frankel, 1994). Treatment of these patients to prevent readmission is difficult (Hawton et al, 1998; Bennewith et al, 2002), with no definite strategies of proven benefit, although a recent study suggested that patients who received a psychosocial assessment were half as likely to poison themselves again (Kapur et al, 2002). Many factors determining such behaviour have been proposed, some of these, such as events or anniversaries, are specific to each patient (Beratis et al, 1996), but other factors relate to external influences and include times of the year (Beratis et al, 1996; Suhail \& Cochrane, 1998) and days of the week (Hulse et al, 2001). Predicting admission patterns may be used to focus medical care and improve management and perhaps even prevent self-poisonings. The aims of this study were to define admission patterns following self-poisoning in a district general hospital in Scotland and to determine, in a subset of patients, what proportion are reviewed by the liaison psychiatry service.

\section{Method}

This was a retrospective case review of 4220 admissions to the medical wards of two Scottish district general hospitals within the same National Health Service (NHS) trust. Patients were selected if they had been admitted following self-poisoning between January 1997 and June
2002. Cases of accidental poisoning were excluded. Patients were identified by coding records with a diagnosis of self-harm due to self-poisoning. A subset of patients admitted over the past 6 -month period were studied to determine what proportion were reviewed by the liaison psychiatry service. The following parameters were recorded: age, gender, day of admission (from midnight), admitting ward, length of stay. The data were entered into a spreadsheet for further analysis (Microsoft Excel version 5). Differences between groups were determined by chi-squared analysis and significance taken at the $5 \%$ level. Data are given as means (s.d.) or as percentages.

\section{Results}

\section{Patient demographics}

The average age was 34 (range 13-94) years. There were more females (2399 (56\%) v. 1821 (44\%); $P<0.001$; Fig. 1). There were 501 patients (12\%) aged $13-18$ years; the majority of these patients were female (351 (70\%) v. 150 (30\%), $P<0.001$; Fig. 2).

\section{Admission details}

There was a total of 3723 (88\%) admissions to a general medical ward. There was a small number of admissions to high dependency areas; either a high dependency unit $(211 ; 5 \%)$ or intensive care unit $(96 ; 2 \%)$. Owing to a shortage of medical beds, there were 190 admissions directly to a bed on a surgical ward. The average stay was longer for those admitted to a high dependency areathan to a general ward ( $3.0 \pm 5.3$ (range $<1-64$ days) v. $1.5 \pm 1.9$ (range $<1-42$ days); $P<0.001$ ). There was no difference in the length of stay between admission to a general medical ward or to a surgical ward. 


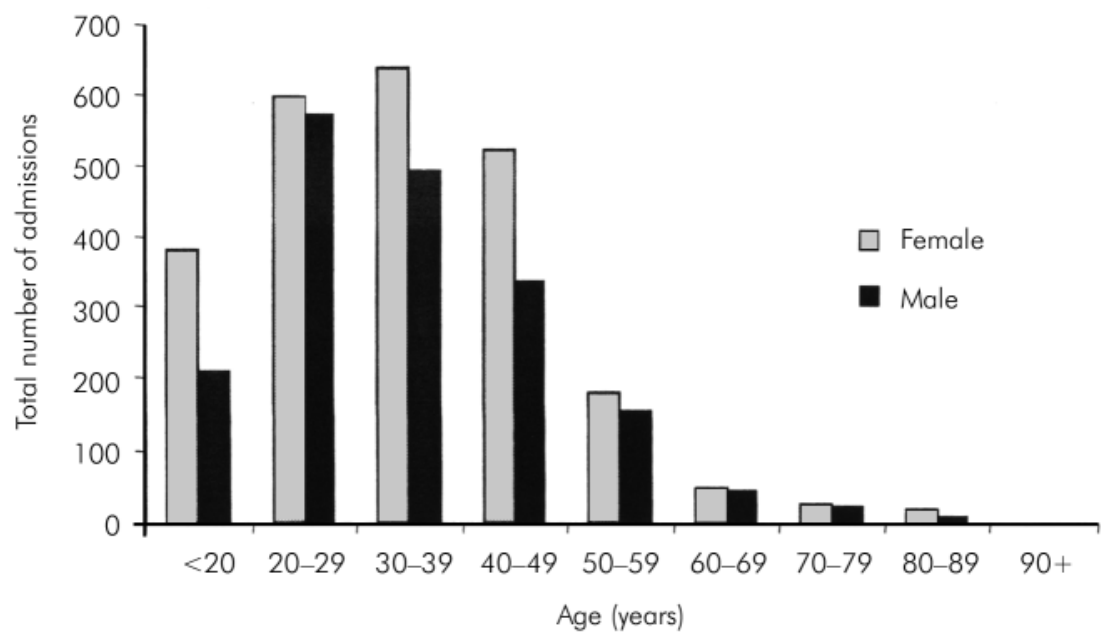

Fig. 1. Age at presentation.

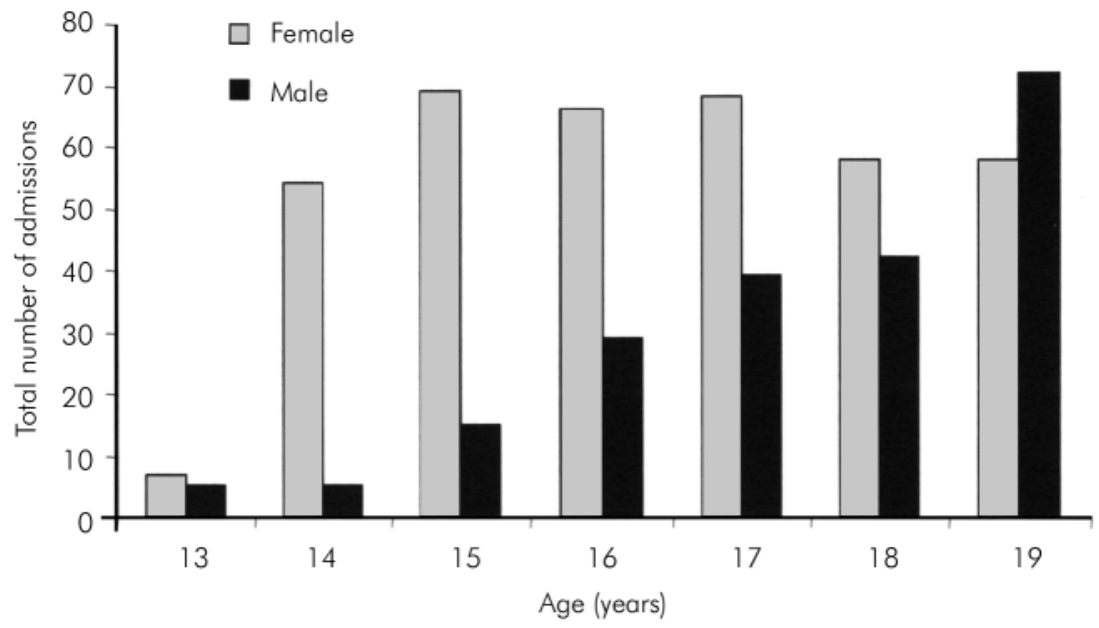

Fig. 2. Gender distribution for admissions of those under the age of 20 years.

\section{Readmissions}

A total of 588 patients had multiple admissions with a diagnosis of self-harm due to self-poisoning during the study period. These patients were responsible for 1790 admissions (42\%); 356 patients had 2 admissions, 121 patients had 3 admissions, 40 patients had 4 admissions, 71 patients had more than 4 admissions and 14 patients had 10 or more admissions (Fig. 3). In general, patients were readmitted early with 234 readmitted within 30 days (Fig. 4). There was no difference in the proportions of females who had multiple or single admissions during the study period (58 v. 57\%, $P=0.8$ ) or mean age of those with multiple or single admissions (34 (s.d. $=12)$ v. 34 (s.d. $=13$ ) years, $P=0.6)$. There was no difference in the numbers of patients who had multiple or single admissions on different days of the week $(P=0.2)$.

\section{Timing of admission}

There were slightly more admissions at the weekend, with 1905 admissions (45\%) occurring between Friday and Sunday $(P=0.002)$. There was no difference in age
( $P=0.07)$ or gender $(P=0.45)$ between those admitted on weekdays or at the weekend.

\section{Number of admissions}

The average number of admissions per month was 43 in 1997. There was an increase to 68 per month in 1998, which remained constant in subsequent years.

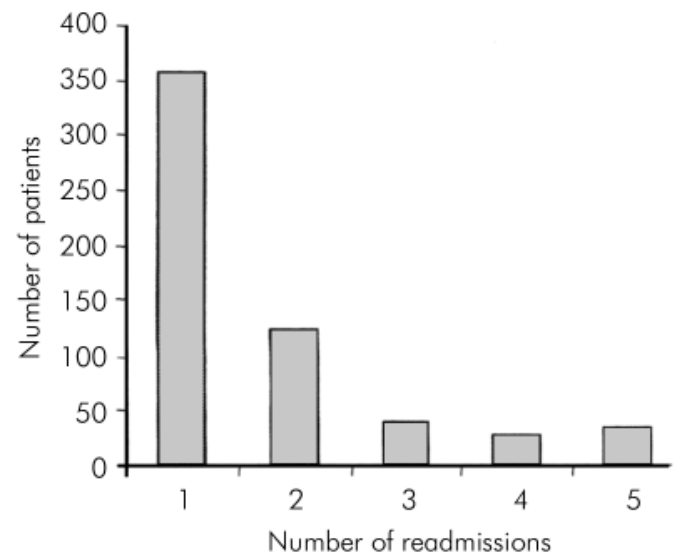

Fig. 3. Frequency of repeat admissions. 


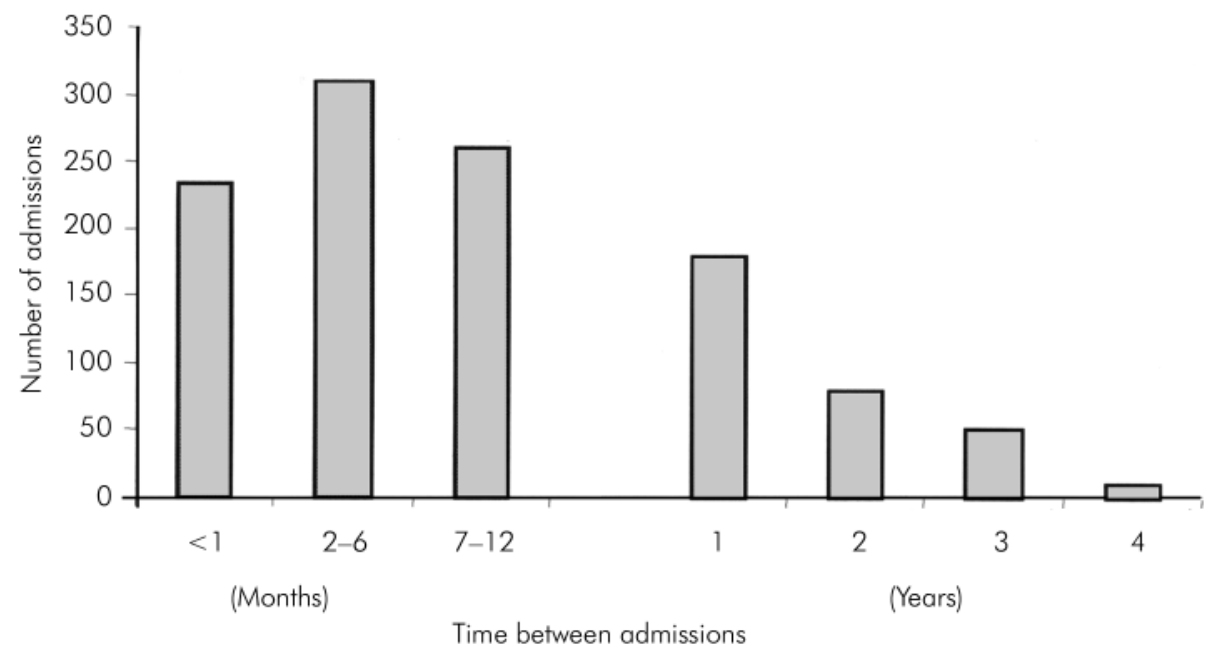

Fig. 4. Time between readmissions.

\section{Psychosocial assessment}

During the latter part of the study a psychiatric liaison nurse was available for referral at one of the hospitals during office hours (09.00 h to $17.00 \mathrm{~h}$ ). Out-of-office hours cover was provided by the psychiatry doctor. Referral patterns were reviewed for this period. During the past 6 months of the study period there were 107 adult admissions to one of the hospitals. Of these 10 (9\%) were not referred, 16 (15\%) self-discharged before they were assessed by the liaison psychiatry service, 43 $(40 \%)$ were reviewed by the liaison nurse and 34 (32\%) were reviewed by the on-call psychiatric doctor.

\section{Discussion}

This study has shown that admission due to selfpoisoning is common in this NHS trust, occurs in young patients with an over-representation of females particularly in the youngest age-group, and many patients have multiple admissions. There are more admissions at the weekend. There were no differences in patient demographics between those who presented at the weekend or those with multiple admissions. A significant proportion of patients do not receive a psychosocial assessment.

Although admission rates due to self-poisoning are reported to be increasing (Bialas et al, 1996; McEvedy, 1997), the numbers of admissions remained similar throughout the period of our study. However, there were a large number of patients with multiple admissions $(20 \%)$. This is consistent with the findings from other studies with readmission rates varying between 9 and $23 \%$ depending on the length of the study and location (Bialas et al, 1996; McEvedy, 1997; Van der Sande, 1997; Hawton et al, 1999). The frequency of readmission soon after the initial admission suggests that the conditions leading or predisposing to the episodes of self-harm are not resolved and that more research is required in this area. Although other studies have demonstrated higher readmission rates among females patients, in our study there was no gender or age difference between patients who had single or multiple admissions.

Our study has demonstrated an alarming number of younger patients, with a particular over-representation of females in the youngest age-group (13-18 years). There was a steady increase in the number of male patients in the 13- to 18-year age-group although the numbers of younger females were consistently higher in this agegroup. These younger patients were admitted to an adult general medical ward for medical care and perhaps this is not appropriate for this age-group. This raises an important issue with regard to providing appropriate facilities and trained staff to cater for the needs of these adolescent patients.

More of our patients were admitted during the weekend days (Friday to Sunday) than the week days although this was a small difference. Weekends are associated with increased alcohol consumption (Engeland \& Kopjar, 2000; Chenet et al, 2001; Hulse et al, 2001), violent accidents (Nunez et al, 2000) and self-harm (Hulse et al, 2001) in many countries. An increase in consumption of alcohol may explain the increase in admissions at the weekend in our patients, although other psychosocial behaviour patterns such as domestic violence may also contribute. This is an important observation as the emergency department and medical wards may also be busier at these times with the non-medical consequences of excessive alcohol misuse. Increased and better-targeted medical resources may be of benefit at these times to cope with the increased numbers of admissions following self-harm.

The majority of patients admitted to the medical unit following self-poisoning will come to no immediate harm, however, this is a recurrent problem associated with significant morbidity and mortality in the medium- and long-term. Patients often present difficult and complex psychosocial problems that are resistant to treatment. This may be exacerbated by a combination of inadequate NHS resources and uncertainty over effective management strategies. However a recent study has demonstrated that a psychosocial assessment at the time of admission can reduce subsequent readmission rates original papers 
(Kapur et al, 2002). In our study $24 \%$ of patients did not receive assessment by the liaison psychiatry service, original either because they were not referred or they had selfpapers

\section{Conclusion}

This study has shown that admission due to selfpoisoning is common, although the absolute numbers did not increase over the time of the study, and that there are more admissions at the weekend. These results support the need for consistent numbers of medical, nursing and ancillary staff during all days of the week to provide optimal care for patients following an episode of self-poisoning. Adequate provision of psychiatric and social support is particularly important to ensure access for a greater number of patients.

\section{Acknowledgements}

We thank the medical records and audit departments at Falkirk and District Royal Infirmary, Scotland for their help in data collection.

\section{Declaration of interest}

None.

\section{References}

BENNEWITH, O., STOCKS, N., GUNNELL, BERATIS, S., GOURZIS, P., GABRIEL, J. D., et al (2002) General practice based (1996) Psychological factors in the intervention to prevent repeat episodes development of mood disorders with a of deliberate self harm: cluster seasonal pattern. Psychopathology, $\mathbf{2 9}$ randomised controlled trial. BMJ, 324, 331-339. $1254-1257$.

BIALAS, M. C., REID, P. G., BECK, P., etal (1996) Changing patterns of selfpoisoning in a UK health district. QuarterlyJournal of Medicine, 89 893-901.

CHENET, L., BRITTON, A., KALEDIENE, $R$., et al (2001) Daily variation in deaths in Lithuania: the possible contribution of binge drinking. International Journal of Epidemiology, 30,743-748.

ENGELAND, A. \& KOPJAR, B. (2000) Injuries connected to violence - an analysis of data from the injury registry. Tidsskrift for den Norske Laegeforening, 120,714-717.

GUNNELL, D. \& FRANKEL, S. (1994) Prevention of suicide: aspiration and evidence. BMJ, 308, 1227-1233.

HAWTON, K., FAGG, J., SIMKIN, S., et al (1997) Trends in deliberate self-harm in Oxford, 1985-1995. Implications for clinical services and the prevention of suicide. British Journal of Psychiatry, $171,556-560$.

HAWTON, K., ARENSMAN, E. TOWNSEND, E., et al (1998) Deliberate self harm: a systematic review of the efficacy of psychosocial and pharmacological treatments in preventing relapse. BMJ, 317, 441-447.

HAWTON, K., HARRIS, L., SIMKIN, S. et al (1999) Deliberate Self-Harm in Oxford. Oxford: University of Oxford.

*Stephen J. Leslie Specialist Registrar, Department of Medicine, Falkirk and District Royal Infirmary, Major Loan, Falkirk FK1 5QE, Scotland, UK, tel: 01324 624000; e-mail: s.j.leslie@ed.ac.uk, Lynn Greig Specialist Registrar, Department of Medicine, Falkirk and District Royal Infirmary

Rhona Mackie Liaison Psychiatry Sister, Department of Medicine, Falkirk and District Royal Infirmary, Michael Gotz Consultant Psychiatrist, Department of Medicine, Falkirk and District Royal Infirmary, Douglas Morrison Consultant Physician, Department of Medicine, Falkirk and District Royal Infirmary 